\title{
A Study on Acceptance of Contraceptive Device Among Female in A Rural Area of Bangladesh and Its Relation with Their Educational Level
}

Shila Rani Das ${ }^{1}$

Chinmay Biswas ${ }^{2}$

A K M Maruf Raza ${ }^{3 *}$

Mehdi Ashik Chowdhury ${ }^{3}$

Md. Sumon Rahman ${ }^{4}$

'Department of Community Medicine Z H Sikder Woman's Medical College Dhaka, Bangladesh.

${ }^{2}$ Department of Dermatology and Veneral diseases Dhamrai Upazilla Health Complex Dhaka, Bangladesh.

${ }^{3}$ Department of Pathology Jahurul Islam Medical College Kishoreganj, Bangladesh.

${ }^{4}$ Department of Surgery Jahurul Islam Medical College Kishoregani, Bangladesh.

*Correspondence to:

\section{Dr. A K M Maruf Raza}

Associate Professor

Department of Pathology Jahurul Islam Medical College

Kishoreganj, Bangladesh.

Mobile : +8801711306123

Email :drmarufraza@gmail.com

www.banglajol.info/index.php/CMOSHMCJ

\begin{abstract}
Background: Bangladesh had an official Family Planning (FP) programme beginning in 1960. Bangladesh has experienced a sevenfold increase in its Contraceptive Prevalence Rate (CPR) in less than forty years from 8\% in 1975 to $62 \%$ in 2014 . However, despite this progress, almost one-third of pregnancies are still unintended which may be attributed to unmet need for family planning and discontinuation and switching of methods after initiation of their use. To find out the acceptance of contraceptive devices among female in rural area of Bangladesh and its relation with their educational level. Methods : A cross sectional descriptive study of fifteen days' duration was conducted among female in rural area of Bangladesh. Participants not willing to respond and pregnant women were excluded. Total of 120 women were selected as study participants. Every woman was interviewed face to face with pre-tested questionnaire after taking informed consent. Results: About $46.92 \%$ were age group 26 to 35 years and $11.11 \%$ were age group more than 36 years of age, $83.96 \%$ were Muslim and $14.81 \%$ were Hindu. Maximum (83.96\%) were married. About $37.04 \%$ were upto class V and $1.23 \%$ were SSC passed. About $27.16 \%$ were class VI to X. About $60.49 \%$ duration of married life 1 to 10 years and $1.23 \%$ married life 30 to 40 years. $86.42 \%$ were use contraceptive device, among them $34.43 \%$ were use condom and $3.28 \%$ were used IUD. About $43.33 \%$ respondents suffer from irregular menstruation and $25 \%$ from menorrhagia, $20.84 \%$ weight gain. About $46.66 \%$ respondents had 2 children and $4.16 \%$ had no child. Conclusion: A renewed commitment from government bodies and independent organizations is needed to implement and monitor family planning strategies in order to ensure the adherence to and provision of the most appropriate contraceptive method for couples.
\end{abstract}

Key words: Contraceptives; Contraceptive device; Contraceptive acceptance; Family planning.

\section{INTRODUCTION}

Bangladesh has experienced a dramatic decline in fertility unprecedented for its poor social and economic conditions. The Total Fertility Rate (TFR) declined from about 7 per cent in the 1970s to around 3.5 per cent in 1993-1994 ${ }^{1,2}$. The Bangladesh Family Planning Programme is recognized as a success story in the contemporary Third World $^{3}$. However, the country still has a high population growth rate and needs to reach replacement-level fertility as soon as possible. The national Contraceptive Prevalence Rate (CPR) of about 45 per cent in 1993 should be raised to over 70 per cent to achieve replacement-level fertility. The family planning programmes could enhance the efficacy of their services by broadening the contraceptive options offered to people in the rural areas. Since individual contraceptive preferences, beliefs, 
and needs vary within populations, service programmes should accommodate the widest possible range of method preferences among the potential contraceptive users ${ }^{4}$. This does not necessarily mean that every family planning programme should have to provide all methods, but the overall programme efforts should be sufficient, so that the prospective users have reasonable, if not absolutely equal, access to a variety of methods ${ }^{5}$. While the programmatic and socioeconomic determinants of contraceptive use at the national and regional level have been studied in Bangladesh, very little is known about the determinants of contraceptive method-choice or method-mix. The objectives of this study is, to find out the acceptance of contraceptive devices among female in rural area of Bangladesh and its relation with their educational level.

\section{METHOD AND MATERIALS}

A cross sectional descriptive study of fifteen days duration was conducted among female in rural area of Bangladesh. The method of sampling was purposive Sampling.

\section{Exclusion criterion:}

i) Participants not willing to respond even after requesting and ensuring confidentiality

ii) Pregnant women. A total of 120 women were selected as study participants.

Every woman was interviewed face to face with pre-tested questionnaire after taking an informed consent. The questionnaire included socio-demographic details and details regarding contraceptive practices. Utmost care was taken to maintain privacy and confidentiality. All collected data were scrutinized with the help of calculator and computer. For descriptive statistics means, standard deviations and range for numerical data and frequency was calculated and presented by table, bar and pie diagram.

\section{RESULTS}

In this study, to assess acceptance of contraceptive device among female in rural area of Bangladesh and its relation with their educational level. About $46.92 \%$ were age group 26 to 35 years and $11.11 \%$ were age group more than 36 years of age, $83.96 \%$ were Muslim and $14.81 \%$ were Hindu. Maximum (83.96\%) were married. About $37.04 \%$ were upto class $\mathrm{V}$ and $1.23 \%$ were SSC passed. About $27.16 \%$ were class VI to X. (Table 1). About $60.49 \%$ duration of married life 1 to 10 years and $1.23 \%$ married life 30 to 40 years (Table II). About $86.42 \%$ were use contraceptive device and $13.58 \%$ were not used. (Figure I). About $34.43 \%$ were use condom and $3.28 \%$ were used IUD. (Figure II). About $43.33 \%$ respondents suffer from irregular menstruation due to use of contraceptive method and $25 \%$ from menorrhagia, $20.84 \%$ weight gain $10.83 \%$ did not suffer from any adverse effect. (Table III). About 46.66\% respondents had 2 children and $4.16 \%$ had no child (Table IV).
Table I : Distribution of respondents according to Sociodemographic characteristic

\begin{tabular}{|c|c|c|}
\hline Age of respondents (In years) & Frequency & Percentage $(\%)$ \\
\hline 25 & 50 & 41.98 \\
\hline $26-35$ & 56 & 46.92 \\
\hline 36 & 14 & 11.11 \\
\hline \multicolumn{3}{|l|}{ Religion } \\
\hline Muslim & 100 & 83.96 \\
\hline Hindu & 12 & 14.81 \\
\hline Christian & 2 & 1.23 \\
\hline \multicolumn{3}{|l|}{ Marital status } \\
\hline Married & 114 & 95.06 \\
\hline Divorced & 6 & 4.94 \\
\hline Widow & 0 & 0 \\
\hline \multicolumn{3}{|l|}{$\begin{array}{l}\text { Educational } \\
\text { status of respondents }\end{array}$} \\
\hline Illiterate & 20 & 16.05 \\
\hline Up to class V & 44 & 37.04 \\
\hline Class VI to $\mathrm{X}$ & 27 & 22.22 \\
\hline SSC Passed & 28 & 23.46 \\
\hline HSC Passed & 1 & 1.23 \\
\hline Graduate and above & 0 & 0 \\
\hline \multicolumn{3}{|l|}{$\begin{array}{l}\text { Educational } \\
\text { status of respondent husband }\end{array}$} \\
\hline Illiterate & 13 & 11.11 \\
\hline Up to class $\mathrm{V}$ & 30 & 24.69 \\
\hline Class VI to $\mathrm{X}$ & 33 & 27.16 \\
\hline SSC Passed & 12 & 9.88 \\
\hline HSC Passed & 28 & 23.46 \\
\hline Graduate and above & 4 & 3.70 \\
\hline
\end{tabular}

Table 2 : Distribution of respondents According to duration of married life $(n=120)$

\begin{tabular}{lcc} 
Duration of married life (In years) & Frequency & Percentage (\%) \\
$1-10$ & 73 & $60.49 \%$ \\
$10-20$ & 28 & $23.47 \%$ \\
$20-30$ & 18 & $14.81 \%$ \\
$30-40$ & 1 & $1.23 \%$ \\
\hline
\end{tabular}

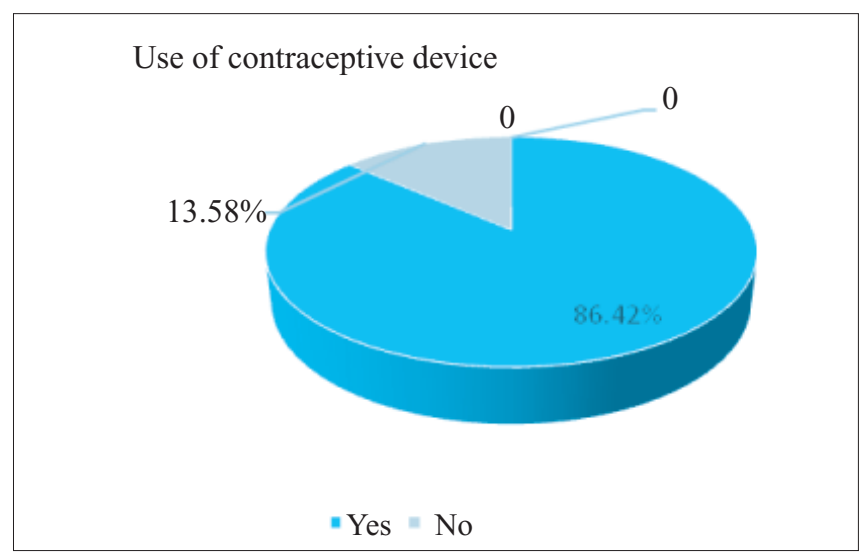

Figure I : Distribution of respondents according to use of contraceptive device 


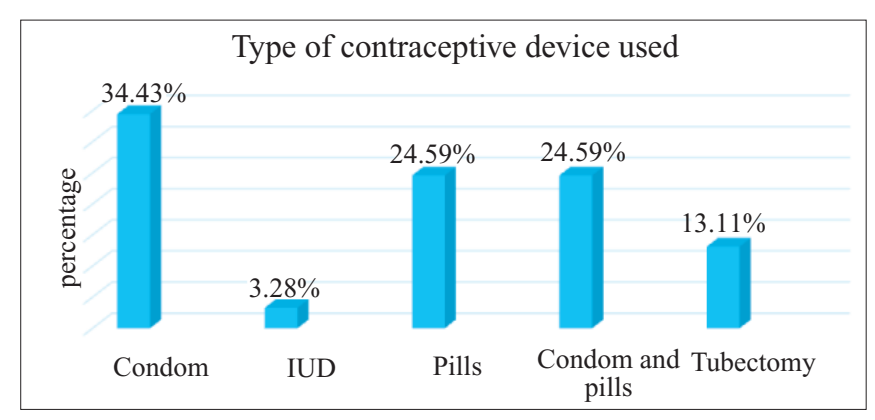

Figure 2 : Distribution of respondents according to type of contraceptive device used

Table 3 : Distribution of respondents according to adverse effect due to use of contraceptive method $(n=120)$

\begin{tabular}{lcc}
$\begin{array}{l}\text { Adverse effect due to } \\
\text { use of contraceptive method }\end{array}$ & Frequency & Percentage \\
Nil & 13 & $10.83 \%$ \\
Irregular menstruation & 52 & $43.33 \%$ \\
Menorrhagia & 30 & $25 \%$ \\
Weight gain & 25 & $20.84 \%$ \\
Total & 120 & $100 \%$ \\
\hline
\end{tabular}

Table 4 : Distribution of respondents according to number of children $(\mathrm{n}=120)$

\begin{tabular}{lcc} 
Number of children & Frequency & Percentage \\
3 and above & 49 & $40.83 \%$ \\
2 & 56 & $46.66 \%$ \\
1 & 10 & $8.33 \%$ \\
nil & 5 & $4.16 \%$ \\
Total & 120 & $100 \%$ \\
\hline
\end{tabular}

\section{DISCUSSION}

This descriptive cross sectional study was aimed at to find out the acceptance of contraceptive devices among 120 females in rural area of Bangladesh and its relation with their educational level. In our study, about $46.92 \%$ were age group 26 to 35 years and $11.11 \%$ were age group more than 36 years of age, More or less similar pictures were found in studies done by Hossain $\mathrm{T}$ et $\mathrm{al}^{6}$. In the current study about $86.42 \%$ were use contraceptive device and $13.58 \%$ were not used. Among them $34.43 \%$ were use condom and $3.28 \%$ were used IUD. This reflects that the oral contraceptive pill and condoms were easy to administer and they were easily available. These findings were almost same with studies done by Saxena, $\mathrm{S}$ et $\mathrm{al}^{7}$. In this study, about $46.66 \%$ respondents had 2 children and $4.16 \%$ had no child which was not similar to study done in Khan Nirmeen Rifa where $(62.63 \%)$ had one or two children. 69 (30.53\%) had three or four children. 13 (5. 75\%) respondents had five or six children. Only $1(0.55 \%)$ respondent had seven or eight or nine children, 39 (14.7\%) had no children ${ }^{8}$. About $43.33 \%$ respondents suffer from irregular menstruation due to use of contraceptive method and $25 \%$ from menorrhagia, $20.84 \%$ weight gain $10.83 \%$ did not suffer from any adverse effect which was similar to the study done in Khan Nirmeen Rifa where 40 (15.09\%) complained of weight gain with the pill and injection, while 20 $(7.54 \%)$ complained of weight loss. 31 (11.69\%) experienced headache with pill. $30(11.32 \%)$ told about irregular menstruation and $23(8.65 \%)$ complained of lower abdominal pain. 7 $(2.64 \%)$ mentioned nausea. Only $2(0.75 \%)$ complained cessation of menstruation, excessive menstruation with injections and IUD each ${ }^{8}$.

\section{CONCLUSION}

Although success of the family planning program in Bangladesh has been widely acclaimed, many challenges still remain. Several demand- and supply-side strategies can help the national family planning program to overcome these challenges.

\section{RECOMMENDATION}

The above findings lead us to some recommendations. Firstly, in order to prevent the gains made in the CPR over the past four decades from being offset by discontinuation and switching of methods, and to promote the use of mix methods, relevant health care providers need to be trained on counseling the couples on method use, options, and accurate information of its risks to allay health concerns. Husbands should be counseled with their wives on long acting and permanent method uptake, and birth planning as they play a major role in decisions to limit/space childbirth and overall issues related to family planning.

\section{DISCLOSURE}

All the authors declared no competing interest. 


\section{REFERENCES}

1. Economic and Social Commission for Asia and Pacific. Population of Bangladesh. New York: United Nations, 1981.

2. Mitra SN, Ali MN, Islam S, Cross AR, Saba T. Bangladesh demographic and health survey Dhaka: NIPORT, Mitra and Associates, and Macro International Inc, 1994.

3. Cleland J, Phillips JF, Amin S, Kamal GM. The determinants of reproductive change in Bangladesh: Success in a challenging environment. Washington D.C. The World Bank, 1994.

4. Phillips JF, Simmons R, Simmons G, Yunus M. Transferring health and family planning service innovations to the public sector: an experiment in organizational development in Bangladesh. Stud Fam Plann. 1984; 15:62-73.

5. Bruce J. Fundamental elements ofthe quality ofcare: a simple frame work. Stud Fam Plann. 1990; 21:61-91.

6. Hossain T, Abedin S, Islam MR; Prevalence of contraceptive use in Naogaon District of Bangladesh; Middle East Journal of Family Medicine. 2008;6(6):7-10

7. Saxena S, Oakeshott P, Hilton S; Contraceptive use among South Asian Women attending general practices in southwest London; British Journal of General Practice. 2002; 392-400.

8. Nirmeen K, Jerifa S. Prevalence of contraceptive use among married women of reproductive age group (15-49 years) in a rural area of Sreepur upazilla under Gazipur district, J Dhaka Med Coll. 2014; 23(1): 7-13. 